\title{
A Study on the Work Method of Moral Education of the Head Teacher in the Network Era
}

\author{
Xiaoyu Kang* \\ Zhejiang University of Finance \& Economics Dongfang College, Haining City 314400, Zhejiang Province, China. \\ E-mail: 785012452@qq.com
}

\begin{abstract}
Head teachers of primary school should fully take advantages of the golden stage, use scientific and effective methods to implement moral education. The network era creates a new moral education environment, which will inevitably bring all kinds of influences to students. Combining the analysis of the influence of the network era on the moral education for primary school students, this paper puts forward the measures to carry out moral education for reference $e^{[1]}$.
\end{abstract}

Keywords: Network Era; Head Teacher of Primary School; Moral Education; Countermeasure

In the network era, primary school students who like to pursue new things are surrounded by new knowledge, new thinking and new ideas every day. The network environment also brings new opportunities to moral education. Information technology breaks the limitation of time and space, and expands the ways and contents of moral education $^{[2]}$. It is both a challenge and an opportunity for traditional moral education. While making good use of this new environment, teachers should do a good job in moral education and improve students' comprehensive quality, so that information technology and moral education work can advance each other.

\section{Analysis of the characteristics of primary school students}

The psychological quality of primary school students is in the period of transition from development to maturity. In this period, they have the psychological characteristics of semi juvenile children. They are not only relatively independent, but also dependent on adults. They begin to have a certain degree of self-consciousness, and still show their childishness now and then. Independence and dependence, self-consciousness and childishness, which are intertwined with each other, constitute the unique psychological characteristics of primary school students, whose thoughts are not stable and mature, and are easy to be interfered by the external environment ${ }^{[3]}$. Therefore, it has become a major difficulty for primary school head teachers of how to carry out moral education under the interference of the network era and how to take effective measures to meet the requirements of moral education.

\section{The problems faced by the teacher in charge of moral education in the network age}

The network culture is very rich, which provides great convenience in the management of the moral education work of the head teacher, but at the same time, it also makes some students lose their way in the network. As a teacher

This is an open-access article distributed under the terms of the Creative Commons Attribution Non-Commercial License

(http://creativecommons.org/licenses/by-nc/4.0/), which permits unrestricted non-commercial use, distribution, and reproduction in any medium,

provided the original work is properly cited. 
in charge of organizing and leading a class, he should be patient, careful and rigorous. It is a challenging and hard work. Some of them have achieved some success, which are recognized by students' parents and praised by the school, while some are far from success with half effort. In present all-round promotion of quality education, the network era brings a great challenge to the head teachers of primary school to do a good job of moral education.

\subsection{Lack of advanced moral education idea}

Some head teachers have not received systematic computer education and English education. Facing the current network technology, they are helpless. Their ability to use the network is even lower than that of students. If they do not update themselves to keep up with the pace of students, it is difficult for them to apply the network to moral education management ${ }^{[4]}$. They are not familiar with the network, do not know how to collect information, or guide students, which is not conducive to their work. Moreover, at present, the cultivation of this aspect is not paid attention to in China, especially for some older teachers. Their working ideas are more traditional and unable to keep pace with the times, and they lack innovation consciousness and time consciousness. Rigid indoctrination on moral education is difficult to arouse students' interest, making the effect of moral education very poor. Some teachers are not active in learning and accepting new things and lack their own sense of crisis, thus unable to achieve the guidance of students.

\subsection{The influence of network on primary school students}

Network has become a powerful driving force to promote the social development in the new century. It is a "double-edged sword". It not only opens a new cultural space, but also brings new challenges to the law and morality, directly affecting the learning life of primary school students and further affecting their growth. Primary school students have a strong demand for innovation, fantasy and entertainment, which is perfectly satisfied by the network. However, the primary school students' psychology is not mature enough, their willpower is poor, they lack immunity to all kinds of temptations, their life experience is shallow, and they lack judgment. The use of the network in the development of moral education provides a platform that is not conducive to the physical and mental development of primary school students.

\subsection{The complexity of network environment}

The Internet is characterized by openness, which also causes the complexity of the network environment. At present, China's network management system is still imperfect, some of which have not yet been established, so it is unable to effectively manage the Internet. China has not formed a perfect network ethics, resulting in the lack of national control and binding force on the network. The emergence of some bad website information has a bad impact on the mental development of primary school students. A variety of software and games, and a virtual environment full of stimulation and challenges affect their outlook on life, values and the world.

\section{Measures to carry out moral education in the network era}

Moral education management in primary school is affected by network information. It is an inevitable trend for students to contact and use the network. Corresponding measures should be carried out to help students establish identification awareness to scientifically and reasonably use network information, thus laying a foundation for the overall development of students. It is bound to provide more suitable network application environment for students, and guarantee the healthy growth of students to improve the management system, improve the management content, explore the management methods, and form the management intervention situation from different perspectives of different dimensions.

\subsection{Perfect the system and follow the principles of moral education management}

To improve the network system, several aspects should considered: first, to regulate the time for students to access the Internet. The primary school students' work pressure is relatively large, and the online time is limited. The head teacher needs to give clear regulations, so the students can use their time reasonably ${ }^{[5]}$. With a fixed time, students can 
not only complete their study tasks, but also arrange their spare time. Second, besides looking up some information on the Internet, primary school students may easily indulge in games. In this respect, teachers should strictly control it, and discuss with students about the schedule. Thirdly, head teachers should at least take part in the study of network moral education, arrange the corresponding tasks, and make the corresponding assessment to guide the students through the network learning. Fourth, to establish a network supervision mechanism. Parents and head teachers are supervisors, who supervise students to access the Internet healthily. Head teachers should often assess and summarize relevant information to criticize and educate students who violate the rules. In real life, education is definitely not only the responsibility of a school or a teacher; instead, it is the responsibility of the whole society. Relying on the strength of students and individuals alone is insignificant. Strong support and full help from the government are in need. The national society should actively build a green Internet access for young people, actively strive for the support of relevant departments, open special Internet channels, and use technical means to block and filter bad websites such as reactionary, pornography, feudal superstition, hacker attacks and viruses. Online records should be monitored and time be controlled, so that the Internet can serve more teenagers ${ }^{[6]}$.

\subsection{Perfect the content and establish the management system of moral education}

In primary school, students are full of curiosity about everything. Teachers should take advantages of the network era, get rid of the shackles of traditional education ideas, and combine the Internet technology to carry out moral education. The class website can be set up so that students can satisfy their curiosity and browse the website independently. On the class website, the head teacher summarizes important information and articles of moral education significance for students, so that students can correctly grasp moral knowledge in the process of browsing the website. Teachers share positive energy articles and cases on the class website, so that students can correctly understand the importance of learning in the network age, correctly view the relationship between online games and learning, and correctly use online self-learning. Teachers can use the home-school contact platform under the network environment to implement home-school communication. The communication between teachers and parents is no longer limited by time and place, which becomes timely, more convenient and quick ${ }^{[7]}$. The teacher can input the text message on the computer to complete the feedback of students' study and life. In addition, the teacher can also give some good ways to educate the parents. This greatly improves the effectiveness of home school interaction.

The establishment of a class website can not only help students form a good habit of browsing the Internet, but also help them to share their learning experience and inner troubles on the class website. Students can enhance emotional exchange. The head teacher can also master the development of students in the recent stage, which is helpful to carry out targeted moral education. According to the requirements of the school's code of conduct, the evaluation form should be formulated to be diversified, with introduction of self-evaluation, mutual evaluation, teacher evaluation and parent evaluation, so as to make the space and scope of moral education wider, enhance the attraction and appeal of education, and improve the effectiveness of moral education ${ }^{[8]}$.

\subsection{Explore ways and innovate management mode of moral education}

The publication of the Ten Year Development Plan of Education Informatization (2011-2020) has made "Internet + moral education" a star of educational informationization. "Renxingbao" is an intelligent campus mobile APP abased on big data, which integrates education, teaching, information, science, dynamic learning and management, and achieves five levels of educational administration departments, schools, teachers, students and parents. In the construction of the Digital School of Chengguan No.1 Primary School in Huanxian County, Zhejiang Province, the data of students, teachers and school moral education working group in daily school are recorded by using the moral education platform of "Yuhuan e school" creatively, which covers the moral education chronicle, class moral education management, comprehensive query and other aspects and forms a unique moral education "big data" in daily moral education management. The internet interaction of No.3 Primary School is implemented in the process ${ }^{[9]}$. The Xuancheng Experimental Primary School in Anhui Province has developed the "virtue online" APP which can be 
downloaded with mobile phone, and promoted it in the urban area, thus constructing a new mode of "Internet + moral education". The new model will bring up students' interest and make teachers give up the boring traditional model ${ }^{[10]}$.

\section{Conclusion}

With the help of big data, artificial intelligence and other scientific and technological means, intelligent moral education management platform can be simplified, make moral education management "visible and touchable", and help school moral education out of the dilemma of "virtual, soft, floating, scattered and disorderly". Moral education needs the network, and the network needs moral education more. In order to ensure children to grow up healthily in the network environment, the teacher in charge of the class who has the most contact with children should give correct and active guidance, actively and effectively carry out the ideological and moral education for primary school students in the network era.

\section{References}

1. Chang G. The problems and measures of the head teacher's moral education in primary school in the network age (in Chinese). Course Education Research 2019; (35).

2. Ji X. Problems and countermeasures of the moral education of the head teacher in primary school in the network age (in Chinese). Practical Electronics 2019; (35): 93.

3. Liu X. The problems and countermeasures of the moral education of primary school teachers in the network age (in Chinese). Teacher's Journal 2019; (S1).

4. Wei D. Research on the creative strategy of the moral education of the head teacher in primary school (in Chinese). Course Education Research 2019; (32)

5. Zhang J. Reflections on the class management and moral education of head teacher in primary school in the new era (in Chinese). Learning Weekly 2018; 373(25): 178-179. doi: 10.16657/j.cnki.issn1673-9132.2018.25.113.

6. Liu Y. How to effectively implement the incentive strategy in the moral education of primary school teacher. (in Chinese). Course Education Research 2018; (14): 67.

7. Liao J. Study on the problems and countermeasures of the moral education work of the headteacher in primary school in the network age (in Chinese). New Course (Primary School) 2017; (11): 25.

8. Long $\mathrm{C}$. The problems and countermeasures of the head teacher's moral education in Tibet class high school in the Internet age (in Chinese). Course Education Research 2017; (34): 171.

9. Chen W. The problems and countermeasures of the moral education work of the head teacher in the network age. The Chinese Journal of ICT in Education 2011; (6): 17-20.

10. Pan J. A brief analysis of the problems and countermeasures faced by the moral education of primary school teachers in the network era. Elementary School Students 2011; (3): 73. 